\title{
FISCALÍA ESPECIALIZADA EN COMBATE A LA CORRUPCIÓN (BREVES COMENTARIOS JURÍDICOS A SU CREACIÓN)
}

\section{Alberto HERRERA PÉREZ ${ }^{1}$}

En los diarios oficiales de la Federación de 10 de febrero de 2014 y 27 de mayo de 2015 se publicaron sendos decretos de reforma, adición y derogación de diversas disposiciones de la Constitución Política de los Estados Unidos Mexicanos en materia político-electoral y combate a la corrupción, respectivamente.

Alta preocupación demuestra el Estado mexicano al modificar su ley fundamental y focalizar uno de los ejes de estas reformas en aspectos dirigidos al combate a la corrupción de los agentes estatales y al fortalecimiento de los órganos de procuración de justicia.

Atacar a fondo el antivalor corrupción que lacera al Estado mexicano resulta impostergable:

Los servidores públicos son agentes del Estado que intervienen en el desarrollo de la función pública, ya sea en el poder ejecutivo, legislativo, judicial o bien dentro de alguno de los diferentes organismos constitucionales autónomos. Los actos de corrupción en los que muchos de ellos incurren, siempre han provocado alarma en la sociedad, pues resulta inaceptable que una actividad del Estado encaminada a satisfacer el bienestar colectivo sea realizada por sujetos ímprobos y deshonestos. ${ }^{2}$

En las reformas que modifican la estructura orgánica de la Procuraduría General de la República se crea la Fiscalía Especializada en Combate a la Corrupción; será este nuevo órgano de procuración de justicia el tema central de los presentes comentarios.

\section{ANTECEDENTES}

\footnotetext{
${ }^{1}$ Licenciado en derecho por la UNAM; especialista en derecho penal por la Universidad Panamericana; especialista en derecho constitucional por la UNAM; maestro en derecho por la Universidad Marista.

${ }^{2}$ Herrera Pérez, Alberto, Delitos cometidos por servidores públicos, 2a. ed., México, Porrúa, 2011.
} 
Esta revista forma parte del acervo de la Biblioteca Jurídica Virtual del Instituto de Investigaciones Jurídicas de la UNAM www.juridicas.unam.mx

De acuerdo con lo dispuesto por el artículo 102, fracción VI, párrafo segundo, del texto constitucional reformado mediante decreto publicado en el Diario Oficial de la Federación (DOF) el 10 de febrero de 2014, la Procuraduría General de la República cambia su denominación a Fiscalía General de la República y se inviste de la naturaleza jurídica de órgano público autónomo, dotado de personalidad jurídica y patrimonio propios, conservando su carácter de Ministerio Público.

Dentro de esta reforma se da vida jurídica a un órgano autónomo denominado Fiscalía Especializada en Combate a la Corrupción (Fiscalía).

El fenómeno de la corrupción de la conducta de los agentes estatales constituye un problema grave y dañino para México, ha vuelto ineficaces los esfuerzos para combatir la pobreza y la desigualdad, ha mermado la eficacia para fomentar el crecimiento económico y se ha constituido en una de las principales causas de propagación del narcotráfico, la delincuencia organizada y la inseguridad que vive actualmente nuestro país. La corrupción es un obstáculo para el desarrollo, además de un problema de eticidad.

Ciertamente, los actos de corrupción no son exclusivos de la actividad o ejercicio del servicio público, ya que pueden incurrir en su comisión entes particulares; lo anterior podría generar confusión respecto del ámbito competencial de la Fiscalía; sin embargo, en el Dictamen de las comisiones unidas de la Cámara de Senadores, Puntos Constitucionales, de Anticorrupción y Participación Ciudadana, de Gobernación y de Estudios Legislativos, segunda, sobre la minuta con proyecto de decreto por el que se reforman, adicionan y derogan diversas disposiciones de la Constitución Política de los Estados Unidos Mexicanos, en materia de combate a la corrupción, leemos:

La Fiscalía Especializada en cuestión, que participará de las características de autonomía de la Fiscalía General de la República, asumirá la función específica de conocer e investigar las

\footnotetext{
${ }^{3}$ Destacable la limitante que el poder reformador establece respecto de las adiciones, reformas y derogaciones de diversos artículos constitucionales en el sentido de condicionar su entrada en vigor a la expedición por el Congreso de la Unión de las normas secundarias respectivas, "siempre que se haga por el propio Congreso la declaratoria expresa de entrada en vigor de la autonomía constitucional de la Fiscalía General de la República" (artículo décimo sexto transitorio de la reforma constitucional publicada en el DOF el 10 de febrero de 2014).

La declaratoria expresa de la entrada en vigor de esta autonomía debe ser a través de una norma general expedida por el propio Congreso de la Unión (ley).
} 
Esta revista forma parte del acervo de la Biblioteca Jurídica Virtual del Instituto de Investigaciones Jurídicas de la UNAM

denuncias por hechos $u$ omisiones presuntamente constitutivo de delito que deriven de posibles actos de corrupción de los servidores públicos, sin demérito de la responsabilidad que corresponda a los particulares que hubieren participado en ellos. Así, la presunta responsabilidad penal de los servidores públicos o de particulares que incurran en hechos de corrupción, será la encomienda de la Fiscalía Especializada. ${ }^{4}$

Lo anterior no deja margen de duda, la creación de esta Fiscalía obedece al combate a la corrupción de los actos ilícitos cometidos por servidores públicos en ejercicio o con motivo de la actividad pública encomendada. ${ }^{5}$

Investir de una denominación tan explícita ("combate a la corrupción") a este nuevo órgano de procuración de justicia permite conjeturar al colectivo social o inclusive al propio indiciado que los actos incoados materia de una imputación se revisten prima facie de la presunción de ser ilegales o corruptos (por más que posteriormente se explique o aclare la situación jurídica), ${ }^{6}$ soslayándose el derecho a la presunción de inocencia que debe ser irrestrictamente respetado por los órganos de poder del Estado. ${ }^{7}$

Tesis 1a. CCCLXXII/2014 (10a.), Gaceta del Semanario Judicial de la Federación, Décima Época, Primera Sala, libro 11, octubre de 2014, t. I, p. 612.

PRESUnCión DE INOCENCIA COMO REgLA DE TRATAMIENTO DEL IMPUTAdO EN MATERIA PENAL. ESTE DERECHO FUNDAMENTAL PUEDE TENER UN EFECTO REFLEJO EN OTROS PROCEDIMIENTOS O ÁMBITOS DONDE SE ESTABLEZCAN CONSECUENCIAS DESFAVORABLES PARA UNA PERSONA SUJETA A PROCESO PENAL. La presunción de inocencia como regla de tratamiento del imputado no sólo determina la forma en la que debe tratarse a éste en el marco del proceso penal, sino que también establece la manera en la que debe tratarse al imputado "fuera del proceso". En este caso, la finalidad de esta vertiente de la presunción de inocencia consiste en impedir que fuera del proceso penal se aplique cualquier tipo de medida desfavorable asociada al simple hecho de que una persona esté sujeta a proceso, evitando así que a través de esas medidas

\section{${ }^{4}$ P. 74}

${ }^{5}$ Sin dejar de advertir que también pueden ser partícipes sujetos particulares y quedar inmersos dentro del ámbito competencial de esta Fiscalía.

${ }^{6}$ Hubiera sido recomendable denominar a este nuevo órgano: Fiscalía Especializada en Actos de Servidores Públicos.

“...la carga final que la adversidad cuelga a sus víctimas es que cuando se les acusa de algo se piensa que bien merecido lo tienen..."; Boecio, Severino, La consolación de la filosofía, Alianza Editorial, 2010, p. 48.

${ }^{7}$ Herrera Pérez, Alberto, El derecho a la presunción de inocencia, México, Porrúa, 2012. 
se haga una equiparación entre imputado y culpable en ámbitos extraprocesales. De esta manera, la presunción de inocencia de la que goza toda persona sujeta a proceso penal puede tener un "efecto reflejo" en otros procedimientos o ámbitos donde se establezcan consecuencias desfavorables a una persona por el simple hecho de estar sujeta a proceso penal.

\section{PERÍMETRO COMPETENCIAL}

El artículo 109 constitucional, reformado por decreto publicado en el DOF el 27 de mayo de 2015, señala: “Los servidores públicos y particulares que incurran en responsabilidades frente al Estado, serán sancionados conforme a lo siguiente: ...".

Establece el poder reformador en este artículo los diversos tipos de responsabilidad (política, penal o administrativa) en que pueden incurrir los servidores públicos y particulares "frente al Estado". 8

Adviértase que las responsabilidades son acotadas respecto de actos en contra del Estado dejando fuera otro tipo de sujetos pasivos que también es posible se configuren como receptores de la ilegal conducta del servidor público.

De acuerdo con lo anterior, en el supuesto que el servidor público con motivo o en ejercicio de sus funciones despliegue una conducta antijurídica no lesiva para el Estado (por ejemplo, dirigida a un particular), la sanción debe instrumentarse de una manera diversa a la establecida en el artículo constitucional que se analiza.

Esto es relevante, pues en este último supuesto la Fiscalía carecería de competencia para conocer de actos ilícitos cometidos por un servidor público "frente a un particular".

Lo anterior se desprende de la lectura del propio artículo que se consulta, en su fracción III, párrafo penúltimo, el cual establece que los órganos internos de control de los entes públicos federales están facultados para presentar ante la Fiscalía Especializada en Combate a la Corrupción denuncias por hechos u omisiones que pudieran ser constitutivos de delito, debiéndose entender por estos últimos aquellos en los que se incurra en responsabilidad penal "frente al Estado", por así ordenarlo el artículo constitucional en comento; ${ }^{9}$ por lo tanto, en el supuesto que estos órganos de control en ejercicio de sus atribuciones detecten hechos $u$ omisiones indebidos en contra de

\footnotetext{
${ }^{8}$ Entendiendo el término "frente" como opuesto o en contra de.

${ }^{9}$ El término "Estado" comprendiendo los tres órdenes de gobierno: federal, estatal y municipal.
} 
Esta revista forma parte del acervo de la Biblioteca Jurídica Virtual del Instituto de Investigaciones Jurídicas de la UNAM

particulares por parte de un servidor público en ejercicio o con motivo de sus funciones, el conocimiento de esos actos no corresponderá al perímetro competencial de la Fiscalía.

En relación con las facultades de este nuevo órgano autónomo, al revestirse de la naturaleza jurídica de un Ministerio Público, le corresponderá, entre otras facultades, la persecución de los delitos cuya naturaleza se derive de actos de corrupción, ${ }^{10}$ solicitar medidas cautelares contra los imputados, buscar y presentar las pruebas que acrediten la participación de éstos, procurar que los juicios federales en materia penal se sigan con toda regularidad y solicitar la aplicación de las penas condignas.

\section{SUJETOS LEGITIMADOS PARA INTERPONER DENUNCIAS ANTE LA FISCALÍA}

El artículo 109 constitucional en su fracción III, párrafos penúltimo y último, establece: Los entes públicos federales tendrán órganos internos de control con las facultades que determine la ley para prevenir, corregir e investigar actos u omisiones que pudieran constituir responsabilidades administrativas; para sancionar aquéllas distintas a las que son competencia del Tribunal Federal de Justicia Administrativa; revisar el ingreso, egreso, manejo, custodia y aplicación de recursos públicos federales y participaciones federales; así como presentar las denuncias por hechos u omisiones que pudieran ser constitutivos de delito ante la Fiscalía Especializada en Combate a la Corrupción a que se refiere esta Constitución.

Los entes públicos estatales y municipales, así como del Distrito Federal y sus demarcaciones territoriales, contarán con órganos internos de control, que tendrán, en su ámbito de competencia local, las atribuciones a que se refiere el párrafo anterior.

De la lectura del párrafo primero entendemos que el órgano interno de control de los entes públicos federales (organismos constitucionales autónomos, dependencias y entidades de la administración pública federal, Procuraduría General de la República y tribunales federales administrativos) ${ }^{11}$ se encuentra legitimado para interponer denuncias por hechos u omisiones que pudieran ser constitutivos de delito.

\footnotetext{
${ }^{10}$ Debe entenderse por estos actos los delitos que cometa el servidor público en ejercicio o con motivo de su actividad al desempeñar un empleo cargo o comisión dentro del servicio público.

${ }^{11}$ Se puede considerar también dentro de esta categoría a cualquier otro ente público de carácter federal.
} 
El párrafo segundo acota al "ámbito de su competencia" a los órganos internos de control, invistiéndolos de facultades para presentar denuncias ante la instancia local correspondiente de hechos constitutivos de delito de servidores públicos en materia local (algún órgano similar, igual, o que ejerza las facultades legales de las que sea investida la Fiscalía).

No obstante lo anterior, en el caso que el órgano interno de control local detecte, en el ejercicio de su actividad fiscalizadora, la probable comisión de un hecho u omisión que pudiera ser constitutivo de delito donde se involucre la violación de leyes federales o el ejercicio indebido de recursos o participaciones federales que administren o ejerzan los estados, municipios, el Distrito Federal o los órganos político-administrativos en sus demarcaciones territoriales, considero que nada impide jurídicamente la interposición de una denuncia por parte del órgano local ante la Fiscalía. ${ }^{12}$

El artículo 79 constitucional en las fracciones I y IV confiere facultad a la Auditoría Superior de la Federación para, derivado de sus investigaciones, promover las responsabilidades que sean procedentes ante la Fiscalía.

De igual manera, el artículo 109 de nuestra ley fundamental otorga esta atribución a la secretaría del Ejecutivo Federal responsable del control interno.

De acuerdo con lo anterior, los sujetos legitimados son:

— Órganos internos de control de los entes públicos federales;

- Órganos internos de control de los entes públicos estatales, municipales, del Distrito Federal y órganos políticos-administrativos de sus demarcaciones territoriales. ${ }^{13}$

- Auditoría Superior de la Federación, y

- Secretaría del Ejecutivo Federal responsable del control interno.

No se confiere legitimación a los particulares para la presentación de denuncias ante la Fiscalía por delitos cometidos por servidores públicos ni aun en el caso en que sean los propios particulares los receptores de la ilegal conducta.

\footnotetext{
${ }^{12}$ Finalmente, la Fiscalía es un Ministerio Público con independencia del ámbito espacial del ejercicio de sus facultades.

${ }^{13}$ Por ejemplo en el caso del ejercicio indebido de recursos federales ya mencionado.
} 
Esta revista forma parte del acervo de la Biblioteca Jurídica Virtual del Instituto de Investigaciones Jurídicas de la UNAM

Deja fuera el poder reformador a los poderes Legislativo y Judicial y, por lo tanto, los órganos internos de control o quien ejerza esta función en estos poderes, no se encuentran investidos de legitimación para interponer denuncias ante la Fiscalía.

Considero que el poder constituyente permanente dejó pasar un gran momento legislativo constitucional al no otorgar facultades a la Fiscalía General de la República (órgano constitucional autónomo) para conocer (a través de la Fiscalía Especializada en Combate a la Corrupción) de actos presuntamente ilícitos cometidos por servidores públicos de los poderes Legislativo y Judicial, y, al no hacerlo, pareciera que el monopolio de la corrupción de los agentes estatales descansa en el Poder Ejecutivo, lo cual no es del todo cierto. ${ }^{14}$

Es importante mencionar, por otra parte, que las determinaciones de la Fiscalía pueden ser recurridas por la Auditoría Superior de la Federación y por la secretaría del Ejecutivo Federal responsable del control interno a través del recurso de revisión, cuyo conocimiento compete a los tribunales colegiados de circuito del Poder Judicial de la Federación.

Esta facultad de impugnación se establece en el artículo 109 constitucional en su penúltimo párrafo, relacionándola con los artículos 20, apartado C, fracción VII, y 104, fracción III, de la Constitución general de la República; no obstante, es necesario advertir que la posibilidad de objetar las determinaciones de la Fiscalía ( $v$. gr. omisiones en la investigación de los delitos, resoluciones de reserva, no ejercicio, desistimiento de la acción penal o suspensión del procedimiento) no es absoluta y debe sujetarse exclusivamente a los aspectos relativos a la reparación del daño atendiendo al contenido del numeral 20 citado. $^{15}$

\footnotetext{
${ }^{14}$ Nada nuevo proponemos, la Auditoría Superior de la Federación (órgano constitucional autónomo) se encuentra investida de facultades cuyo ejercicio puede extender hacia los poderes constituidos (Ejecutivo, Legislativo y Judicial), como entidades fiscalizadas (artículo 20., fracción IX, de la Ley de Fiscalización y Rendición de Cuentas de la Federación).

${ }^{15}$ Me parece que debieron ampliarse los supuestos para impugnar las determinaciones de la Fiscalía a otros aspectos punitivos (prevención especial, prevención general, etcétera) relevantes para el correcto y eficaz ejercicio del servicio público del Estado mexicano y no limitarlos a la reparación del daño (que desde luego no deja de ser importante).
} 


\section{ALGUNOS ASPECTOS A CONSIDERAR EN LA EXPEDICIÓN DE LEYES SECUNDARIAS}

Establece el artículo segundo transitorio de la reforma constitucional, publicada el 27 de mayo de 2015, el tiempo de un año (contado a partir de la entrada en vigor del Decreto) para la aprobación de las leyes generales respectivas.

Para el caso de las adiciones, reformas y derogaciones a los artículos 79, 108, 109, $113,114,116$, fracción V, y 122, base quinta, constitucionales, entrarán en vigor en la misma fecha que lo hagan las leyes referidas en el transitorio segundo.

\section{PROPUESTAS LEGISLATIVAS}

- La Fiscalía debe contar con el marco jurídico suficiente para investigar y perseguir de forma efectiva los delitos en materia de corrupción.

- Es recomendable, a fin de no crear un vacío legal, identificar con precisión el perímetro competencial de la Fiscalía y señalar los supuestos normativos bajo los cuales puede encuadrarse un acto de corrupción (para evitar posibles incompetencias o inclusive contradicciones con el código punitivo), que puedan derivar en un no ejercicio de la acción penal o una doble punición (prohibida por el texto constitucional).

- Debe otorgarse facultades a este nuevo órgano para realizar la persecución de otros delitos que converjan en la comisión de actos de corrupción. ${ }^{16}$

- Es necesario reglar la facultad de atracción de esta Fiscalía respecto de asuntos locales que revistan importancia y trascendencia.

- Para una adecuada seguridad jurídica, debe normarse expresamente los casos en que los órganos internos de control de los entes públicos locales se encuentran legitimados para interponer denuncias ante la Fiscalía.

- Sería oportuno conceder facultades al Comité Coordinador del Sistema Nacional Anticorrupción para presentar denuncias ante la Fiscalía, o bien, permitir que recomendara la presentación de las mismas.

- Debe ponderarse conferir legitimación a los particulares para la presentación de denuncias ante la Fiscalía por delitos cometidos por servidores públicos en los casos

\footnotetext{
${ }^{16}$ Por ejemplo el caso de la comisión de los delitos de cohecho y delincuencia organizada.
} 
en que sean los propios particulares los receptores de la ilegal conducta; ello con la finalidad de concentrar en un solo órgano el combate a la corrupción y no disgregarlo en varios entes públicos.

- La necesaria autonomía del titular de esta nueva Fiscalía, para ejercer de manera eficaz la encomienda constitucional, se ve protegida por una limitante a su nombramiento y remoción al ser posible objetar ambas acciones por parte del Senado de la República; por lo tanto, la ley secundaria debe señalar con absoluta precisión las causas de remoción de este servidor público, así como los tiempos para objetar su nombramiento y tutelar la garantía de audiencia y debido proceso, en su caso. 